\title{
A conceptual model for root water extraction by taking into account root depth, root density, and vulnerability to xylem cavitation
}

\author{
Alessia Amabile ${ }^{1}$, Brunella Balzano ${ }^{1}$, Marco Caruso ${ }^{2}$, Alessandro Tarantino ${ }^{1}$ \\ ${ }^{1}$ Department of Civil and Environmental Engineering, University of Strathclyde, Glasgow, UK \\ ${ }^{2}$ Dipartimento di Ingegneria Strutturale, Politecnico di Milano, Milano, Italy
}

\begin{abstract}
Vegetation plays an important 'hydrological' role in the stabilisation of geostructures. Water extracted through the root system by evapotranspiration at the leaves increases soil suction and, hence, soil shear strength. Current 'boundary condition' models for root water extraction are based on the concept of 'wilting point', i.e. plants cease to extract water when threshold suction is attained. The concept of wilting point, however, is a long-standing misconception. There is clear evidence that evapotranspiration may take place at suctions higher than the conventional $1500 \mathrm{kPa}$ wilting point and that evapotranspiration, although significantly reduced, does not cease under wilting conditions. This paper presents a conceptual model for water root extraction based on the concept of SPAC (Soil-Plant-Atmosphere-Continuum). Actual evapotranspiration is modelled by taking into account the 'resistances' of bulk soil, soil-root interface, and xylem. It is shown that the model can capture qualitatively very well observed SPAC responses in terms of actual evapotranspiration pattern, and suction evolution at the soil-root interface and xylem.
\end{abstract}

KEYWORDS: numerical modelling, suction, vegetation, unsaturated soils.

\section{INTRODUCTION}

This paper presents an analysis of the hydrological effects of vegetation on soil water extraction. The soilplant-atmosphere continuum (SPAC) model is first introduced by describing the water flow through the different components of the system, focusing on (i) the bulk soil, (ii) the soil-root interface and (iii) the plant.

When the system is not able to accommodate the evaporative demand of the atmosphere, the water flow rate is determined by the water availability of the system and not by the atmospheric conditions.

The difference between evapotranspiration in energy limited and water limited regime is highlighted. The present paper focuses on the evapotranspiration in water limited regime, giving a simple analytical model to better understand the hydraulic behaviour of the different components of the SPAC system.

\section{THE SPAC MODEL}

Soil, plant, and atmosphere taken together form a physically integrated, dynamic system, which has been called the soil-plant-atmosphere continuum (SPAC) by Philip (1966). In this system, water flow takes place from regions of higher to regions of lower water potential $h$ (Figure 1).

This flow involves water movement in the soil toward the roots, absorption into the roots, transport through the roots to the xylem and through the xylem to the leaves, evaporation in the intercellular air spaces of the leaves, vapour diffusion through the substomatal cavities and stomatal openings to the quiescent boundary air layer in contact with the leaf surface, and through it to the turbulent air layer surrounding the plant, whence the vapour is finally transported to the external atmosphere.

Each component of the SPAC system represents a resistance to the water flow and its behaviour has to be described through its hydraulic properties.

When a plant loses water to the atmosphere, the potential of water in the leaf drops at the sites of evaporation. A gradient in water potential is formed that drives water from the soil through the plant. Stomata do not usually respond to the reduction in water potential necessary to maintain the transpiration stream unless water supply to the leaves is limited by the hydraulic conductivities of bulk soil, soilroot interface, or xylem which progressively decrease as evapotranspiration takes place. Then stomata begin to close rapidly to limit the water loss in the leaf in response to the limited water supply. This 
behaviour justifies the assumption that the leaf is always in saturated conditions.

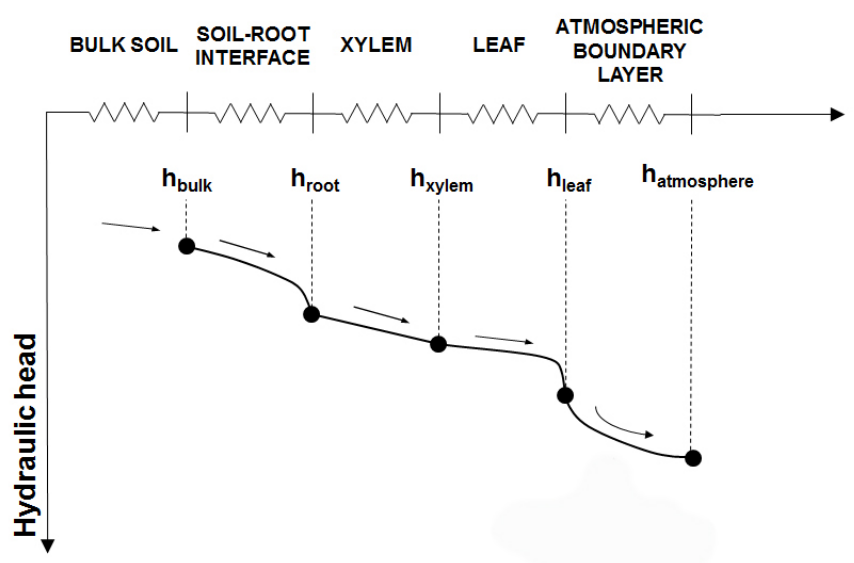

Figure 1. Hydraulic heads and resistances in the SPAC system.

When water is available, evapotranspiration occurs at its maximum rate, defined by the potential evapotranspiration. It is mainly controlled by meteorological conditions (net radiation, air temperature, relative humidity), and is therefore said to be energy limited. It may be estimated through the PenmanMonteith equation (Monteith 1965):

$$
P E T=\frac{1}{\lambda} \frac{\Delta \cdot R_{n}+\rho_{a} \cdot c_{p} \cdot p_{v 0}(z) \cdot[1-R H(z)] / r_{a}}{\Delta+\gamma \cdot\left[\left(r_{a}+r_{c}\right) / r_{a}\right]}
$$

where $\lambda\left[\mathrm{J} \mathrm{kg}^{-1}\right]$ is the latent heat of vaporisation of water at the air temperature $T(\mathrm{z}), P E T\left[\mathrm{~kg} \mathrm{~m}^{-2} \mathrm{~s}^{-1}\right]$ the potential evapotranspiration rate, $\Delta\left[\mathrm{Pa}^{\circ} \mathrm{C}^{-1}\right]$ the slope of the saturation vapour pressure curve at the air temperature $T(\mathrm{z}), \gamma\left[\mathrm{Pa}^{\circ} \mathrm{C}^{-1}\right]$ the psychrometric constant at the air temperature $T(\mathrm{z}), R_{\mathrm{n}}\left[\mathrm{W} \mathrm{m}^{-2}\right]$ the rate of net radiation, $\rho_{\mathrm{a}}$ the air density $\left[\mathrm{kg} \mathrm{m}^{-3}\right], c_{\mathrm{p}}\left[\mathrm{J} \mathrm{kg}^{-1}{ }^{\circ} \mathrm{C}^{-1}\right]$ the specific heat of air, $p_{\mathrm{v} 0}[\mathrm{~Pa}]$ the saturation vapour pressure at the air temperature $T$ at the elevation $z, p_{\mathrm{v}}[\mathrm{Pa}]$ the actual air vapour pressure at the elevation $z, R H$ the relative humidity at the elevation $z, r_{\mathrm{a}}\left[\mathrm{s} \mathrm{m}^{-1}\right]$ the resistance term for the aerial transport of water vapour from the canopy, $r_{\mathrm{c}}$ [s $\mathrm{m}^{-1}$ ] the surface resistance of the transpiring crop. Air properties can be assumed to be constant $\left(\rho_{\mathrm{a}}=1.2 \mathrm{~kg} \mathrm{~m}^{-3}\right.$; $c_{\mathrm{p}}=1000 \mathrm{~J} \mathrm{~kg}^{-1}{ }^{\circ} \mathrm{C}^{-1}$ ) whereas the psychrometric variables $\Delta, \gamma, \lambda$, and $p_{\mathrm{v} 0}$ are dependent on temperature.

When water is available, evapotranspiration occurs at its maximum rate, defined by the potential evapotranspiration. As the drying power of the air is increased, the suction at the soil surface increases, and the rate at which water moves upward and evaporates increases accordingly. But eventually a limit is approached beyond which ET can no longer increase. Evapotranspiration is then controlled by the ability of the system to transmit water, regardless of the drying power of the atmosphere. It is therefore said to be in water limited regime.

\section{WATER LIMITED EVAPOTRANSPIRATION}

In the water limited regime, evapotranspiration is limited by water availability in the SPAC system.

In order to understand in which part of the system the limiting condition is reached, this paper presents an analytical method to derive the value of the limiting evapotranspiration in the bulk soil, at the soilroot interface and in the plant system which is composed by the xylem and the leaf.

\subsection{Bulk soil}

The limiting condition in the bulk soil is reached when the suction on the ground level goes to infinite (Figure 2).

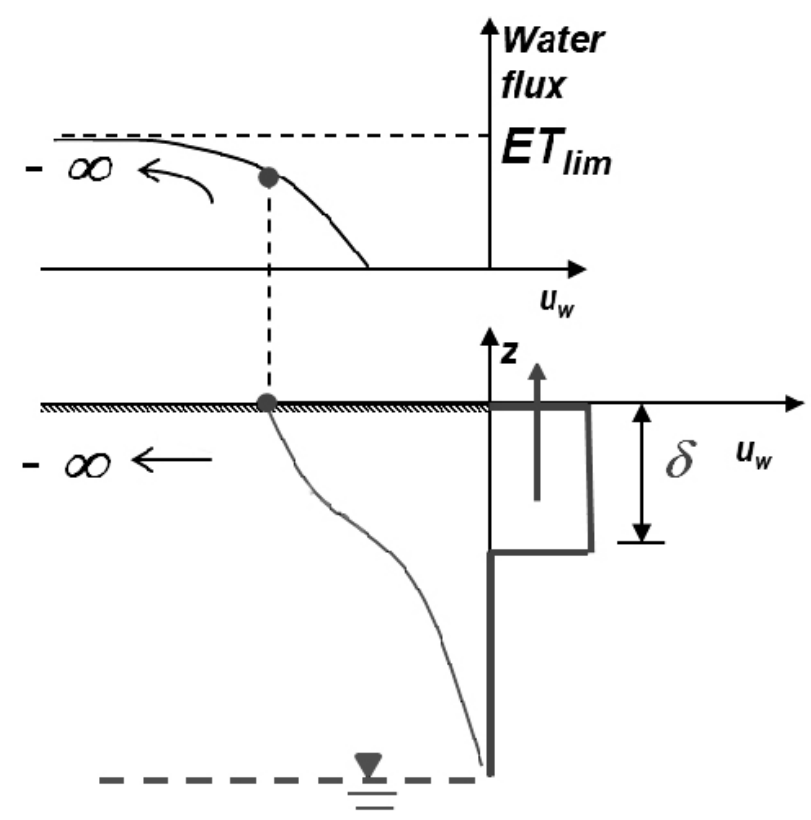

Figure 2. Limiting condition in the bulk soil.

For one-dimensional flow, Richards' equation can be written as:

$$
\frac{\partial \theta}{\partial t}=\frac{\partial}{\partial z}\left[K\left(u_{w}\right) \frac{\partial h}{\partial z}\right]-\mathrm{S}(z)
$$

where $\mathrm{S}(\mathrm{z})$ is the sink term representing the root water uptake, $\mathrm{K}\left(\mathrm{u}_{\mathrm{w}}\right)$ is the hydraulic conductivity of the soil.

The analytical solution to this equation, in transient state conditions, found by Yuan and $\mathrm{Lu}$ (2005), has been used in this paper.

This solution is based on the following assumptions:

- hydrostatic initial condition;

- exponential model for the retention and hydraulic conductivity curves:

$$
K\left(u_{w}\right)=K_{s} e^{\alpha \frac{u_{w}}{\gamma_{w}}}
$$


where $\alpha$ is a parameter depending on pore size distribution in the soil and $\mathrm{K}_{\mathrm{s}}$ is the hydraulic conductivity in saturated conditions.

The $\mathrm{ET}_{\text {lim }}$ expression derived by this solution is the following:

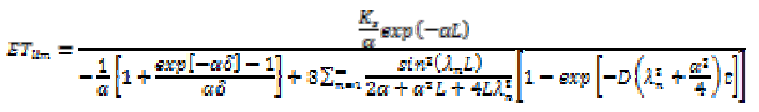

\subsection{Soil-root interface}

At the soil-root interface the limiting condition is reached when the suction at the interface goes to infinite (Figure 3).

To analyse the soil-root system the cylindrical single root model by Passioura (1988) has been considered. In steady state conditions the radial flow equation can be written as:

$$
\frac{\partial \theta}{\partial t}=\frac{1}{r} \frac{\partial}{\partial r}\left(r K \frac{\partial h}{\partial r}\right)=-\frac{q}{r}-\frac{\partial q}{\partial r}
$$

where $r$ is the radial coordinate in the reference system which has origin in the centre of the root and $\mathrm{q}$ represents the flux in the single root $\mathrm{q}_{\text {root. }}$. To convert the flux in the single root $\mathrm{q}_{\text {root }}$ to evapotranspiration the root system geometry has to be considered. The following expression can be used:

$$
q_{\text {root }}=\frac{q}{2 \pi r_{\text {root }} \delta N}
$$

where $r_{\text {root }}$ is the radius of the root, $\delta$ is the length of the root and $\mathrm{N}$ is the root density expressed as number of roots per square meter.

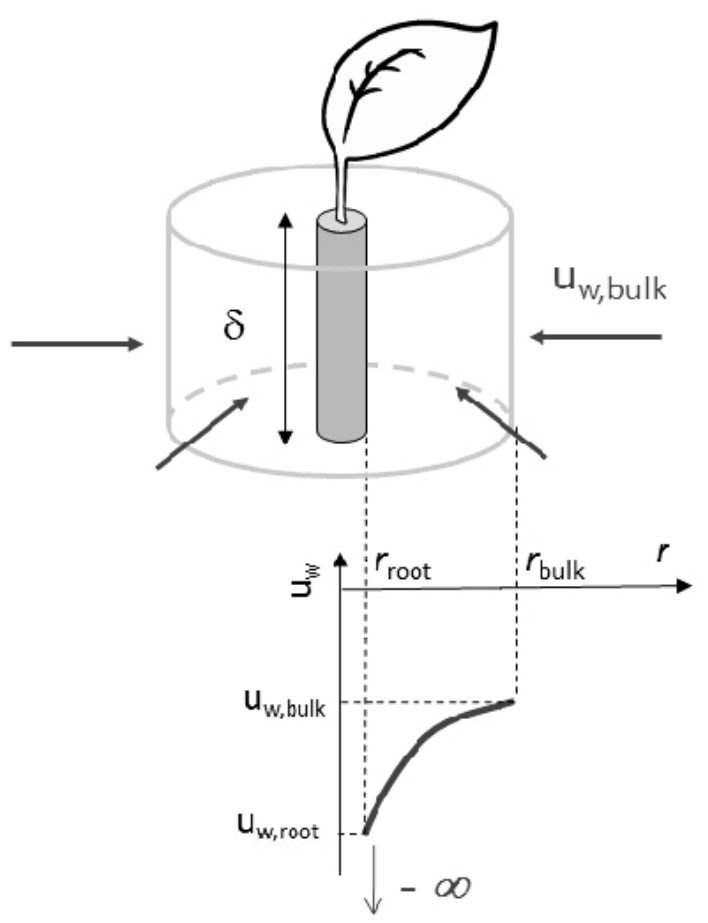

Figure 3. Limiting condition at soil-root interface.

The solution to equation (5) is given by the following expression:

$$
q_{\text {root }}=-\frac{K_{s}}{\alpha} \frac{1}{r_{\text {root }}} \frac{e^{\alpha h_{\text {root }}}-e^{\alpha h_{\text {bull }}}}{\ln \left(\frac{r_{\text {root }}}{r_{\text {bulk }}}\right)}
$$

where $u_{\mathrm{w}, \text { bulk }}$ and $\mathrm{u}_{\mathrm{w}, \text { root }}$ are the pore water pressure in the bulk soil and in the root respectively.

The limiting value for the evapotranspiration is given by the following expression:

$$
E T_{\text {lim }}=\frac{K_{s}}{\alpha} \frac{e^{\frac{w_{W}, b u l k}{\gamma_{w}}}}{\ln \left(\frac{r_{r Q Q t}}{r_{b u l k}}\right)} 2 \pi \delta N
$$

\subsection{Plant}

The analysis of the plant system, composed by xylem and leaf, is based on the following assumptions:

- the water pressure in the leaf never exceeds the air-entry value $u_{\mathrm{w}, \text { leaf; }}$

- the hydraulic behaviour of the plant system is defined by a linear equation:

$$
q_{\text {root }}=D\left(u_{w_{i} \text { root }}-u_{w_{l} l \text { leaf }}\right)
$$

where D is the hydraulic conductivity of the xylem expressed in $\mathrm{m}^{*} \mathrm{~s}^{-1} * \mathrm{kPa}^{-1}$.

The limiting condition in the plant system is therefore reached when the suction in the leaf reaches the limit value $\mathrm{u}_{\mathrm{w}, \text { leaf }}$.

By combining the equations (7) and (9) the relationship between $\mathrm{u}_{\mathrm{w}, \text { bulk }}$ and $\mathrm{q}_{\mathrm{root}}$ is derived.

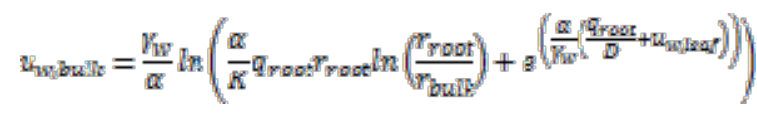

To convert qroot in ET, equation (6) is applied.

\section{CONCLUSIONS}

The analytical model developed in this paper can be used to analyse the water flow in the SPAC system when evapotranspiration occurs in water limited regime. The equations derived allow to understand in which part of the system the limiting condition is reached.

The value of $\mathrm{ET}_{\text {lim }}$ in the bulk soil given by equation (4), is depending on the time. In other words it means that, for a given value of ET, this equation 
can give the maximum period of time in which the bulk soil can accommodate the imposed flux. With the same approach the equation (10) can be used to derive the maximum value of the bulk suction for a given evapotranspiration.

For a given value of ET, in order to understand if the limiting condition has been reached in the bulk soil or in the plant a transient state analysis can be performed for the period of time $t$ derived from the equation (4); the value of the pore water pressure obtained from the analysis can then be compared to the one given by equation (10). A practical application of this approach can be seen in Balzano et al.

\section{REFERENCES}

Alonso, E.E., Vaunat, J. \& Gens, A. (1999). Modelling the mechanical behaviour of expansive clay. Engineering Geology, 54: 173-183. 